\title{
Antimicrobial Properties of Optimized Microwave-assisted Pyroligneous Acid from Oil Palm Fiber
}

\author{
Fatimatul Zaharah Abas ${ }^{1}$, Zainul Akmar Zakaria ${ }^{1 *}$, Farid Nasir Ani ${ }^{2}$ \\ ${ }^{1}$ Institute of Bioproduct Development, (IBD), Faculty of Chemical and Energy Engineering, Universiti Teknologi Malaysia, 81310, Skudai, Johor, Malaysia. \\ ${ }^{2}$ Department of Thermodynamics and Fluid Mechanics, Faculty of Mechanical Engineering, Universiti Teknologi Malaysia, 81310, Skudai, Johor, Malaysia.
}

\begin{tabular}{|c|c|}
\hline ARTICLE INFO & ABSTRACT \\
\hline Article history: & The demands for an antimicrobial agent of natural origin has increasingly grown in recent years due to the adverse \\
\hline Received on: 14/01/2018 & health effects from the long-term application of conventional chemical-based agent. To date, there are very few reports \\
\hline Accepted on: $15 / 04 / 2018$ & available on the use of pyroligneous acid produced in optimized condition, as antimicrobial agent. Thus, this study \\
\hline Available online: $30 / 07 / 2018$ & $\begin{array}{l}\text { reports on the evaluation of the antimicrobial properties of oil palm fiber-derived pyroligneous acid produced using } \\
\text { microwave heating at optimum condition (MWPA). The optimized MWPA was concentrated and extracted using ethyl }\end{array}$ \\
\hline $\begin{array}{l}\text { Key words: } \\
\text { Pyroligneous acid, } \\
\text { microwave, pyrolysis, } \\
\text { antimicrobial, phenolic, } \\
\text { OPF. }\end{array}$ & $\begin{array}{l}\text { acetate and was further determined for its antimicrobial properties against Gram positive and Gram negative bacterial } \\
\text { strains through Minimum Inhibitory Concentration (MIC) and Minimum Biocidal Concentration (MBC) analysis. } \\
\text { Results obtained shows that MWPA exhibited high inhibition zone that varied between } 13 \pm 0.58 \text { to } 28.67 \pm 0.88 \mathrm{~mm} \\
\text { toward all strains screened in the present study with low range of MIC value from } 0.651 \pm 0.13 \text { to } 1.563 \pm 0.00 \mathrm{mg} / \mathrm{ml} \text {. } \\
\text { This indicated that CPAEA MWPA derived from OPF exhibited a strong antimicrobial activity and might be projected } \\
\text { as alternative natural source as antimicrobial agent. }\end{array}$ \\
\hline
\end{tabular}

\section{INTRODUCTION}

The antimicrobial agent is a substance that has the capability to kill or inhibit the growth of microorganisms. Many researchers have focused on elucidating the potential of natural products as a new source of bioactive molecules due to the failure of alternative drug discovery methods to deliver many lead compounds in key therapeutic areas such as metabolic diseases and anti-infective (Nasir et al., 2015). To date, natural products are still one of the major sources to provide new drug molecules mainly due to its rich phenolic contents that is a proven antimicrobial compound. Various researchers have investigated the potential of a wide range of plant sources and microbial extracts, essential oils, pure secondary metabolites and newly synthesized molecules as an antimicrobial agent using many well-published methods (Balouiri et al., 2016).

Pyroligneous acid (PA) is a crude condensate obtained by condensing the smoke produced during pyrolysis process

\footnotetext{
${ }^{*}$ Corresponding Author

Zainul Akmar Zakaria, Institute of Bioproduct Development, (IBD),

Faculty of Chemical and Energy Engineering, Universiti Teknologi

Malaysia, 81310,Skudai, Johor, Malaysia.E-mail: zainul@ibd.utm.my
}

of plant biomass under the absence of oxygen. This liquid is a complex mixture of highly oxygenated liquid consisting of $80-90 \%$ of water and $10-20 \%$ organic compounds with a distinctive smoky odor as well as reddish-brown and acidic $\mathrm{pH}$ in nature. Moreover, PA normally comprised of a complex mixture namely guaiacols, catechols, syringols, phenols, vanillins, acetic acid, ester, derivatives of furan and pyran (Wanderley et al., 2012). In fact, the presence of phenolic compounds, organic acid as well as carbonyls has generally contributed to the antimicrobial activity of PA. According to Karou et al. (2005), polyphenols are well documented to have microbicide activities against a huge number of pathogenic bacteria. In addition, oxidized polyphenols also have inhibitory activity against bacterial growth. Few factors have been related to the mechanism of polyphenols toxicity against microbes such as cell envelope transport proteins, inhibition of hydrolytic enzymes (proteases and carbohydrolases) and nonspecific interactions with the carbohydrates (Mirkarimi et al., 2013). Amongst examples for PA derived from plant biomass that have been shown containing antimicrobial properties include PA from Rhizophora apiculata (Ibrahim et al., 2014), oil palm shell (Achmadi et al., 2013) and Eucalyptus urograndis (Araújo 
et al., 2018). However, very few reports are available on the antimicrobial properties of PA derived from oil palm fiber (OPF) that was produced using microwave-assisted heating in optimum condition, which is ultimate to be elaborated in this study.

\section{MATERIALS AND METHODS}

\section{The extraction process of microwave-assisted pyroligneous acid (MWPA)}

MWPA was produced from the pyrolysis of oil palm fiber at optimized condition $\left(540^{\circ} \mathrm{C}\right.$ within 23 minutes of holding time with $86.74 \mathrm{~g}$ of $\mathrm{AC}$ load; data for optimization work not shown as not the focus for this study). It was then filtered through Whatman filter paper No.4 followed by extraction using $99.5 \%$ of ethyl acetate (EA) using method proposed by Rungruang and Junyapoon (2010) with slight modification as follows; the MWPA:EA mixtures (1:1.5) was homogenously shaken for 3 minutes under ambient condition in a $250 \mathrm{ml}$ separatory funnel. It was allowed to stand around 30 minutes where the top layer (EA extract) was collected in a $250 \mathrm{ml}$ flat bottom flask while the remaining residues in the sample were re-extracted twice using fresh EA. The combined supernatants were then concentrated using rotary evaporator (Laborota-4003, Heidolph) for 10-15 minutes at $80^{\circ} \mathrm{C}$ where the pooled and concentrated extracts were termed as a concentrated pyroligneous acid extract of ethyl acetate (CPAEA) of MWPA.

\section{Characterization of MWPA}

The CPAEA was analyzed using GC-MS (QP500, Shimadzu) according to Zhai et al. (2015) with a modification as follows; $100 \mu \mathrm{l}$ of CPAEA was dissolved in $2 \mathrm{ml}$ of $95 \%$ methanol (HPLC grade) and was filtered using $0.2 \mu \mathrm{m}$ membrane syringe filter before it was injected into the GC-MS column. About $1 \mu \mathrm{l}$ of the sample was injected into the capillary column (BXP-5) with a diameter of $29.4 \mathrm{~m} \times 0.25 \mathrm{~mm}$, the film thickness of $0.25 \mu \mathrm{m}$, the flow rate of $2 \mathrm{ml} / \mathrm{min}$ and he as the carrier gas. The sample was injected using the splitless injection conducted at a split ratio of $25: 1$ with $300^{\circ} \mathrm{C}$ of injection temperature according to the following scheme; $50^{\circ} \mathrm{C}$ for $2 \mathrm{~min}$ with a heating rate of $10^{\circ} \mathrm{C} /$ min up to $300^{\circ} \mathrm{C}$. The final temperature around $325^{\circ} \mathrm{C}$ was held for 10 minutes and the total runtime for each sample was around 37 minutes. The electron ionization used was $70 \mathrm{eV}$ in mass spectrometry (MS) detection and the mass fragment was detected between 400 and $500 \mathrm{~m} / \mathrm{z}$. The ion source temperature and transfer line were set at $200^{\circ} \mathrm{C}$ and $300^{\circ} \mathrm{C}$ respectively. The GS-MS profile obtained was identified using database available in the National Institute of Standards and Technology (NIST), USA.

\section{Antimicrobial activity assay}

\section{Bacterial strain screening}

The antimicrobial properties of optimized CPAEA were evaluated against four different bacterial strains namely; Bacillus cereus ATCC 10876, Staphylococcus aureus ATCC 25923, Lactobacillus plantarum WICC B18 and Escherichia coli ATCC 25922. All cultures were subcultured on selective agar slants namely, Simmon Citrate Agar (SCA, Merck), Hicrome ${ }^{\text {TM }}$ Bacillus Agar (HBA, Fluka) McConkey Agar (MA, Merck), Baird-Parker
Agar (BPA, Merck) and de Man, Ragosa, Sharpe Agar (M.R.S.A, Oxoid) prior to incubation at $37^{\circ} \mathrm{C}$ for $24 \mathrm{hrs}$. All cultures were kept at $4^{\circ} \mathrm{C}$ until further used. All strains were sub-cultured in nutrient agar (20 g/L, Merck, Germany) every two weeks to maintain viability.

\section{Disk diffusion method of antimicrobial assay}

The disk diffusion method was carried out according to Ibrahim et al. (2014) with a slight modification as follows; sufficient amount of a 24-hours bacterial culture (grown on respective agar plates) was transferred (using cotton swab) into a series of sterilized bottle samples $(27 \mathrm{~mm} \times 61 \mathrm{~mm})$ until the turbidity reaches the equivalent of $0.5 \mathrm{McFarland}$ standard $\left(1.5 \times 10^{8}\right.$ cells/ $\mathrm{mL}$ ) or can be accurately measured using a spectrophotometer with a 1-cm light path at $625 \mathrm{~nm}$ which corresponding to an absorbance reading of 0.08 to 0.1 (Bandet et al., 2014). Then, $100 \mu \mathrm{l}$ of the cell suspension was pipetted onto a nutrient agar plate and was distributed uniformly using the spread plate technique. Following this, sterilized antibiotic disc (Whatman, United Kingdom) with $6 \mathrm{~mm}$ diameter was impregnated with $30 \mu \mathrm{L}$ of $100.0 \mathrm{mg} / \mathrm{mL}$ of CPAE extract, prior to air dried (in a sterilized condition). It was then placed onto the nutrient agar and incubated for 24 hours at $37^{\circ} \mathrm{C}$. The experiments were carried out in triplicates and the antimicrobial activities were evaluated by measuring the diameter of the halo-zone formation around the disc. Chloramphenicol (30 $\mu \mathrm{g} / \mathrm{mL}$, Oxoid) and methanol were used as positive and negative control respectively.

\section{Relative percentage inhibition}

The relative percentage inhibition growth of CPAEA towards all strains was determined using the following equation Naz and Bano (2012);

Relative percentage inhibition of test extract $=(100 \times(X-Y)) /(Z-Y)$,

where $X$ denotes total area of inhibition of the test extract, $Y$ is the total area of inhibition of the solvent, and $Z$ is the total area of inhibition of the standard drug. The total area of the inhibition was calculated using area $=\pi r^{2}$, where $r$ is the radius of the zone of inhibition.

\section{Minimal inhibitory concentration (MIC)}

The MIC evaluation was analyzed based on the microdilution method using 96 plates well according to Elshikh et al. (2016) and Wiegand et al. (2008) with some modifications. Initially, $100 \mu \mathrm{L}$ of nutrient broth (NB) was transferred into each of the 96 wells microplate $\left(\operatorname{Kartell}^{\circledR}\right)$. Then, $100 \mu \mathrm{L}$ of CPAEA was pipetted and transferred into the $1^{\text {st }}$ well and thoroughly mixed. After well mixing, $100 \mu \mathrm{L}$ of the mixture was transferred into the $2^{\text {nd }}$ well to make it a two-fold dilution. This procedure was repeated until the $10^{\text {th }}$ well. Then, $20 \mu \mathrm{L}$ inoculum of each bacterial suspension (in sterile distilled water equivalent to $0.5 \mathrm{McF}$ arland solution) was pipetted into each well from the $1^{\text {st }}$ to the $11^{\text {th }}$ well. The plate was then incubated at $37^{\circ} \mathrm{C}$ for 24 hours and the MIC value was taken as the first well showing no visible growth by using the naked eyes (Balouiri et al., 2016). The experiments were carried out in triplicates for CPAEA and the results were expressed 
as means of three experiments. The $11^{\text {th }}$ well contained nutrient broth and inoculum while the $12^{\text {th }}$ well contained nutrient broth only. Both acted as control and blank respectively.

\section{Minimum biocidal concentration (MBC)}

The analysis of MBC was immediately carried out by streaking the mixture content directly from wells with concentrations higher than the MIC value as recommended by Elshikh et al. (2016) using a sterilized cotton swab. The mixture content of each strain that has a concentration higher than the MIC well was inoculated on a nutrient agar plate followed by incubation at $37^{\circ} \mathrm{C}$ for $20-24 \mathrm{hrs}$. Each plate was divided into three compartments to make it as triplicate and the $\mathrm{MBC}$ value was determined when no microbial growth was detected.

\section{RESULT AND DISCUSSION}

\section{Chemical constituent of CPAEA from OPF}

The chemical composition of CPAEA was determined using GCMS analysis. The ion chromatogram as well as the relative contents of the compounds identified as depicted in Figure 1 and Table 1, respectively. From the 15 major peaks observed, phenol was identified as the dominant compound with a peak area of approximately $68.25 \%$ of the total fractions. Higher fractions of phenol compound observed was high due to the high final temperature applied $\left(540^{\circ} \mathrm{C}\right)$ during pyrolysis process as agreed by Wei et al. (2010) and Huang et al. (2013). This was followed by the 2-Butenedinitrile, (E)- which accounted to $4.75 \%$ of the total fractions. Other compounds detected include benzene, alkene, pyran, toluene, hexane, pyridine, amide and nitrogen compounds.

Table 1: Major chemical constituents in optimized CPAEA of MWPA via GCMS analysis.

\begin{tabular}{|c|c|c|c|c|}
\hline Peak & Retention Time (min) & Compound Identification & Area (\%) & MW (g/mol) \\
\hline 1 & 1.1897 & Benzene & 1.4133 & 78.11 \\
\hline 2 & 1.2241 & 2-Butenedinitrile, (E)- & 2.2886 & 78.074 \\
\hline 3 & 1.2527 & 2-Butenedinitrile, (E)- & 2.4593 & 78.074 \\
\hline 4 & 1.4758 & Acetamide, 2-fluoro-(amide) & 3.11 & 77.058 \\
\hline 5 & 1.9222 & 2-Cyclopenten-1-one (ketone) & 1.1671 & 82.102 \\
\hline 6 & 2.4314 & 2H-Pyran, 3,4-dihydro-(pyran) & 0.9209 & 84.118 \\
\hline 7 & 2.8091 & Phenol & 68.2507 & 94.111 \\
\hline 8 & 2.9292 & 1,2-Difluoroethane (alkane) & 0.2637 & 66.051 \\
\hline 9 & 3.324 & Cyclohexane, 1,4-dimethyl-, cis- & 0.6028 & 112.216 \\
\hline 10 & 3.5128 & 2-Chloro-5,5-dimethyl-1-phenyl-3-hexen-1-ol & 1.7171 & 236.737 \\
\hline 11 & 3.7246 & o-Toluidine(toluene) & 4.1198 & 107.16 \\
\hline 12 & 3.9535 & 2(1H)-Pyridinone, 1-methyl-(pyridine) & 3.5875 & 109.1259 \\
\hline 13 & 5.1551 & 2-(2,2-Dimethylvinyl)thiophene (thiophene) & 1.3834 & 138.230 \\
\hline 14 & 6.2308 & 2-(2,2-Dimethylcyclopropyl)thiophene (thiophene) & 0.7413 & 152.257 \\
\hline 15 & 19.5058 & 1H-1,3-Benzimidazole-1-acetonitrile, 2-(difluoromethyl)- & 0.7705 & 207.180 \\
\hline
\end{tabular}

*MW = molecular weight.

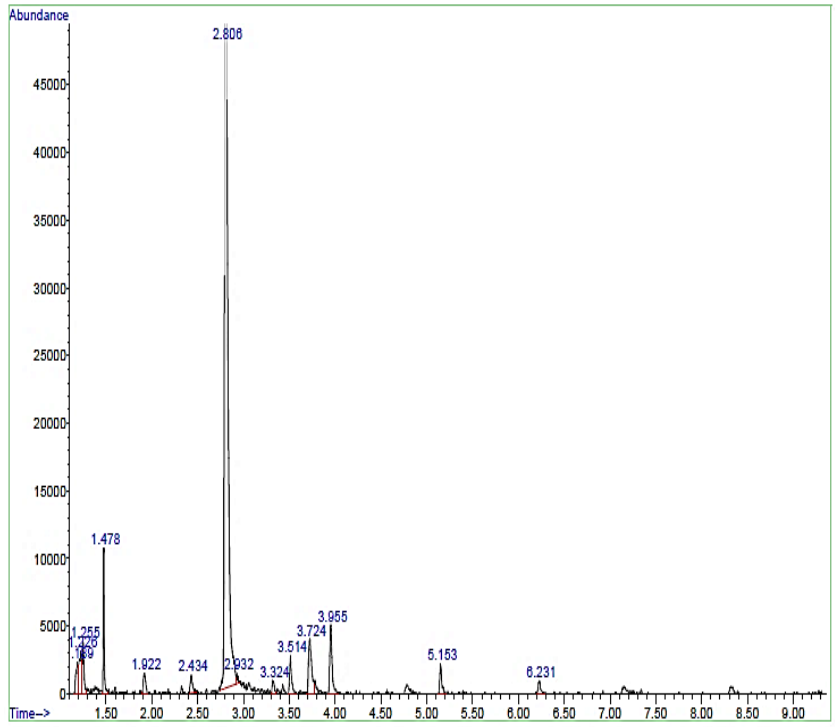

Fig. 1: GCMS ion chromatogram of optimized CPAEA of MWPA from oil palm fiber.
A similar observation was reported by Mathew et al. (2015) with $69.5 \%$ of phenol present in the dichloromethane extract of pineapple waste-based pyroligneous acid. Phenol compounds were derived mostly from the thermal degradation of lignin with the cross-linked structures of the phenylpropane units cracking such as hydroxyl-and methoxy-substituted from macromolecular lattice in lignin during the pyrolysis process. In addition, the presence of phenols, ketone, and organic acid compounds also gives an indication of the potentially high antimicrobial properties of CPAEA (Ibrahim et al., 2013). Another constituent such as pyran and its derivatives which includes 2H-pyran, 3,4-dihydro- and 2(1H)-pyridinone, 1 -methyl- accounted for $4.51 \%$ of the total fractions, of which these compounds contributed to the brown color and smoky odor of the PA (Montazeri et al., 2013). Interestingly, the polycyclic aromatic hydrocarbon $(\mathrm{PAH})$ such as pyrene and phenanthrene, that is highly carcinogenic, were not present in the CPAEA which indicated that highly aromatized pyroligneous acid can be produced from microwave-assisted pyrolysis heating. 


\section{Antimicrobial properties analysis}

\section{Inhibition zone activity of CPAEA}

All screening bacteria strains observed on a selective agar plate after $24 \mathrm{hr}$ incubation was depicted as in Figure 2. The antimicrobial activity of the optimally-produced CPAEA was evaluated based on the diameter of inhibition zone towards all strains tested. The inhibition zone activity of CPAEA towards all strains tested obtained after $24 \mathrm{hr}$ incubation at $37^{\circ} \mathrm{C}$ was depicted as in Table 2. It was observed that the inhibition zones on all agar plates were clearly formed around the disc that has been impregnated with CPAEA. The largest diameter for inhibition zone, DIZ (22-32 mm) was obtained for disc impregnated with chloramphenicol $(30 \mathrm{ug} / \mathrm{ml})$ compared to the CPAEA $(13-28 \mathrm{~mm})$. However, no inhibition zone was observed for disc added with methanol. The antimicrobial activity of CPAEA as observed in this study can be attributed to the presence of phenolic compound and its derivatives as suggested by Ibrahim et al. (2013) and Montazeri et al. (2013). According to Mohapatra et al. (2011), the bacterial strain was sensitive to the sample extract if the DIZ was greater than $11 \mathrm{~mm}$ and resistance to the sample if the diameter was less than 7.
Thus, it explained that all the bacterial strains tested in the present study were sensitive and susceptible to CPAEA, which is also comparable to that reported by Araújo et al. (2018) where a DIZ in the range of 15 to $25 \mathrm{~mm}$ was recorded when the pyroligneous acid from wood of Eucalyptus urograndis and Mimosa tenuiflora were tested against Escherichia coli, Pseudomonas aeruginosa (ATCC 27853), Staphylococcus aureus (ATCC 25923), Candida albicans (ATCC 10231) and Cryptococcus neoformans. It this study, the growth of $E$. coli ATCC 25922 was strongly inhibited by CPAEA (DIZ value of $28.67 \pm 0.88 \mathrm{~mm}$ ) followed by L. plantarum WICC $\mathrm{B} 18(16.67 \pm 0.33 \mathrm{~mm}), S$. aureus ATCC $25923(16.33 \pm 0.33$ $\mathrm{mm})$ and $B$. cereus ATCC $10876(13 \pm 0.58 \mathrm{~mm})$. This relatively substantial antimicrobial capability of CPAEA can be due to the presence of hydroxylated phenolic compounds such as catechol (two OH-groups) and pyrogallol (three $\mathrm{OH}$-groups) which is known to be highly toxic to the microorganism (Cowan, 1999). Fullerton et al. (2011) reported that the antimicrobial activities were due to the oxidized phenol and hydroxyl group present on the phenolic ring. The hydroxylation process increased with increasing number of hydroxyl group, which in turn increased the antimicrobial activity.

Table 2: Inhibition zone activity by disc diffusion method of CPAEA MWPA towards different strains after 24 hrs at $37^{\circ} \mathrm{C}$.

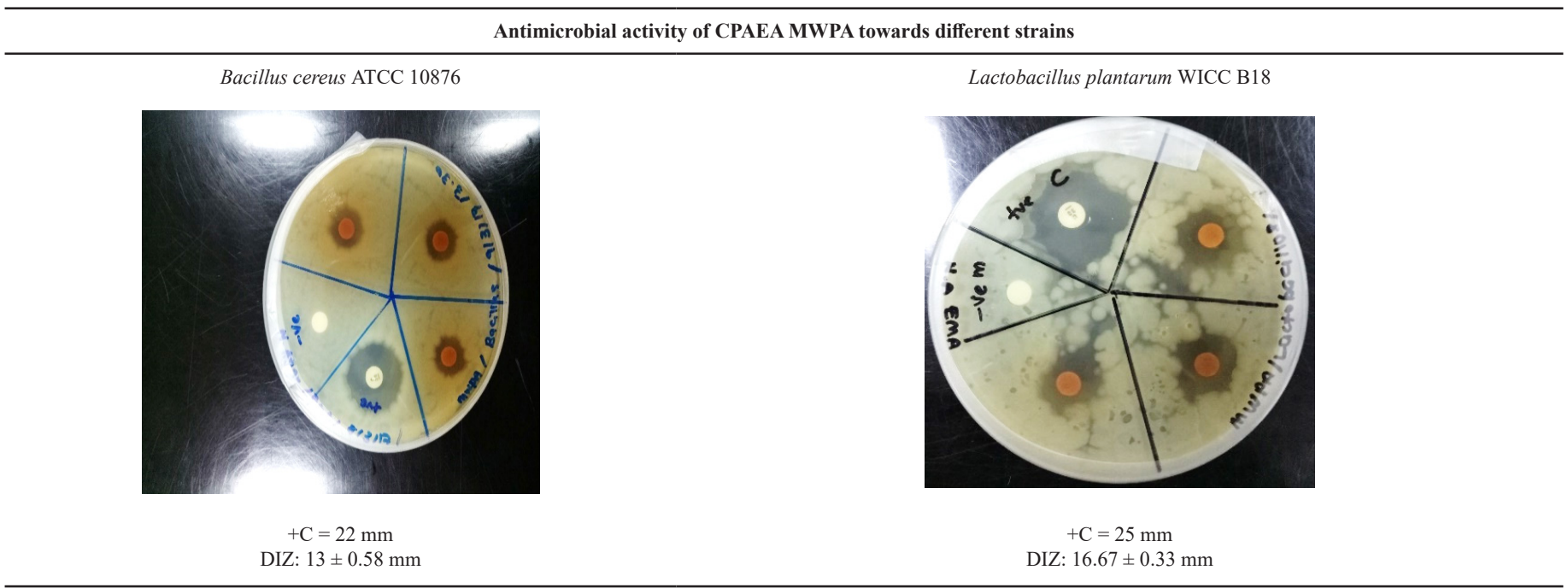

Escherichia coli ATCC 25922

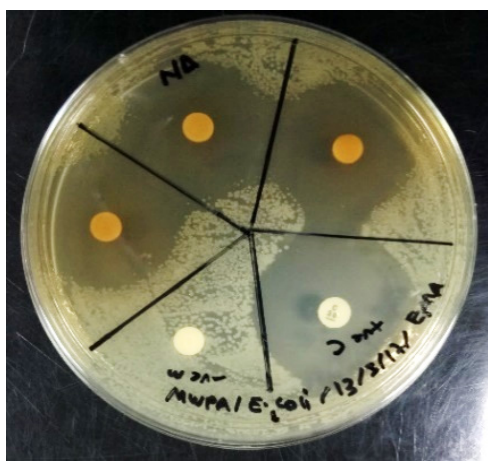

$+\mathrm{C}=32 \mathrm{~mm}$ DIZ: $28.67 \pm 0.88 \mathrm{~mm}$
Staphylococcus Aureus ATCC 25923

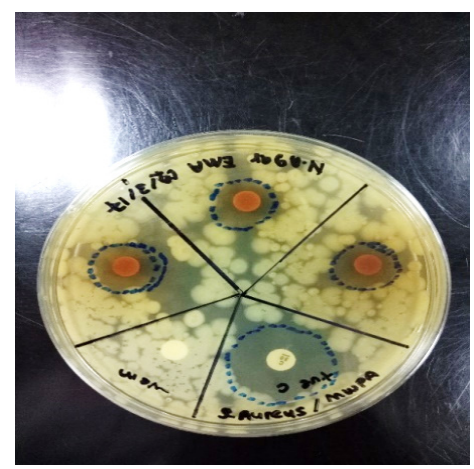

$+\mathrm{C}=23 \mathrm{~mm}$ DIZ: $16.33 \pm 0.33 \mathrm{~mm}$

\footnotetext{
${ }^{*}+\mathrm{C}=$ chloramphenicol $(30 \mathrm{ug} / \mathrm{ml})$ as positive control, $\mathrm{n}=3$.
} 
The result from the present study is comparable with that reported by other researchers such as Wei et al. (2010) where the application of PA produced from walnut shell resulted in DIZ values of $21.2 \mathrm{~mm}$ and $18.6 \mathrm{~mm}$ against $E$. coli and $S$. aureus respectively. Another report by Mohapatra et al. (2011) showed the higher susceptibility of Gram-negative bacteria towards raw honey extracted with DIZ value of $26.49 \pm 6 \mathrm{~mm}$ for $E$. coli MTCC 1687 compared to Gram-positive bacteria such as $S$. aureus MTCC $737(8.58 \pm 3 \mathrm{~mm})$ and B. cereus MTCC 430 (11.11 $\pm 6 \mathrm{~mm})$. One plausible reason for this condition is the effect of solvent extract used. Mehmood et al. (2012) reported that ethyl acetate extract of PA produced from Cichorium intybus seeds has strong antimicrobial activity against $E$. coli with DIZ about 22.5 $\mathrm{mm}$ compared to $21 \mathrm{~mm}$ against $S$. aureus. This situation could be due to Gram-negative bacteria having a much thinner cell wall compared to Gram-positive bacteria, hence allowing more contacts between phenolic compounds, as that present in CPAEA, to rupture the cell wall which would ultimately lead to the cell lysis. Comparatively, Yang et al. (2016) found that S. aureus 985 was more susceptible to PA from Litchi chinensis compared to E. coli 25257 with DIZ of $19 \mathrm{~mm}$ and $15.2 \mathrm{~mm}$ respectively. However, no further reasoning was conclusively included in this matter.

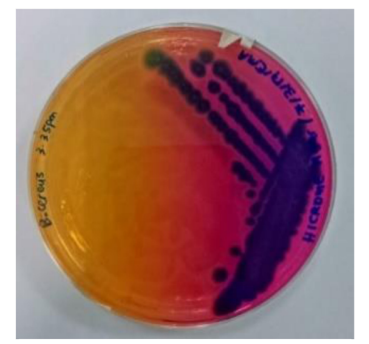

B. cereus ATCC 10876
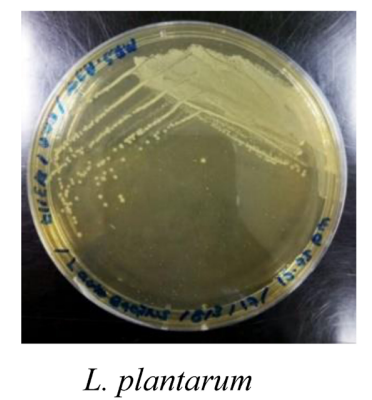

WICC B18

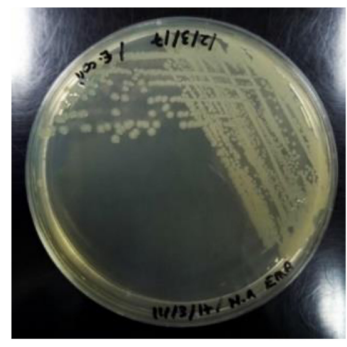

E. coli

ATCC 25922

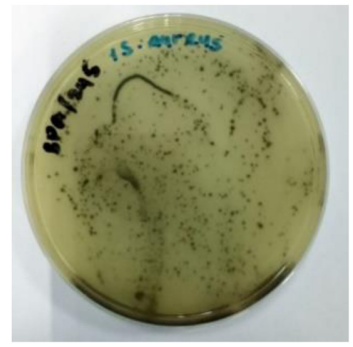

S. aureus

ATCC 25923

Fig. 2: Bacteria cultured on selective agar plate after $24 \mathrm{hr}$ incubation at $37^{\circ} \mathrm{C}$.

\section{Relative inhibition of CPAEA}

The relative growth of inhibition of CPAEA towards all strains was evaluated against chloramphenicol $(30 \mathrm{ug} / \mathrm{ml})$ and the results obtained are as shown in Figure 3. CPAEA managed to significantly inhibit the growth of E. coli ATCC 25922 with percentage inhibition of $79.55 \%$, followed by $S$. aureus ATCC 25923 (46.79\%), L. plantarum WICC B18 (41.07\%) and B. cereus ATCC 10876 (29.69\%). A previous study by Naz and Bano (2012) on the methanolic extracts of Ricinus communis leaf showed relatively high inhibition percentage of around 69.2 to $75 \%$ against $S$. aureus, B. subtilis, $P$. aeruginosa and $K$. pneumoniae. Meanwhile, the crude extract of Calotropis gigantea leaves demonstrated relative percentage inhibition around 46.04 to $188.52 \%$ against $S$. aureus, $K$. pneumoniae, $P$. aeruginosa, $S$. aureus and E. coli (Kumar et al., 2010). This might be due to the different plant extract used, of which the plant extract from leaves has a higher phenolic compound that leads to high inhibition activity towards strains tested and $C$. gigantea leaves were well published as a medicinal purpose. Thus present finding shows that the ability of CPAEA MWPA to penetrate the cell wall led to the successful antimicrobial activity due to the fact that there were specific interactions between cell wall compartments with the bioactive compounds in plant extract itself as agreed by Hyldgaard et al. (2012). In addition, the antimicrobial activity varies considerably and might be mediated by a variety of antimicrobial compounds in plant extract used as suggested by Ibrahim and Lim (2015).

\section{Evaluation of minimum inhibitory concentration}

The result of MIC observation after $24 \mathrm{hr}$ incubation at $37^{\circ} \mathrm{C}$ for all CPAEA towards bacteria strains noticed that the $11^{\text {th }}$ well for all strains was highly turbid which indicated there was a visible bacterial growth compared to the absence of bacteria growth in $12^{\text {th }}$ well that display a clear broth solution. In addition, the turbidity for all CPAEA against bacterial strains in each plate was observed from $1^{\text {st }}$ to $10^{\text {th }}$ well and the well of lowest concentration at which no turbidity formed has been marked as the MIC. The MIC values for CPAEA against all bacterial strains after $24 \mathrm{hrs}$ of incubation are as summarized in Figure 4. CPAEA showed good antibacterial activity against all strains with MIC values ranging from 0.651 to $1.563 \mathrm{mg} / \mathrm{ml}$. It was found that E. coli ATCC 25922 was the most susceptible to CPAEA with MIC value of $0.651 \pm$ $0.13 \mathrm{mg} / \mathrm{ml}$, followed by $S$. aureus ATCC $25923(0.78 \pm 0.00 \mathrm{mg} /$ $\mathrm{ml}$ ), and $1.56 \pm 0.00 \mathrm{mg} / \mathrm{ml}$ for both $B$. cereus ATCC 10876 and L. plantarum WICC B18. This finding correlated well with the results obtained for DIZ of which $E$. coli shows the highest DIZ among other strains tested. Similar trends of observation were also reported by Yang et al. (2016) where generally, the highest DIZ exhibited by sample extract would demonstrate the lowest MIC value and vice versa. In addition, Mohapatra et al. (2011) also reported the MIC value exhibited by raw honey extracted against E. coli and B. cereus were approximately at $0.625 \mathrm{mg} / \mathrm{ml}$.

Comparatively, the MIC value obtained in the present study was lower than MIC value for PA extract towards antifungal activity (3.13-6.25 mg/ml) reported by Ibrahim et al. (2013b). This directly indicates that CPAEA from OPF exhibited stronger antimicrobial effect against bacteria than fungi. A similar situation was also supported by Cunha et al. (2017) where lowest MIC value indicates that the plant extract has strong bioefficacy and antimicrobial potential towards bacterial strains. It is noteworthy that value of MIC generally does not give an indication of the mode of action such as cidal or static. This was due to the viable 
cells might be still in the MIC well even without visible growth if the antimicrobial agent had a bacteriostatic effect against the bacterial strains tested as suggested by Wiegand et al. (2008). This makes it imperative to carry out the microbial biocidal concentration (MBC) assay in order to ascertain the bactericidal effect of CPAEA.

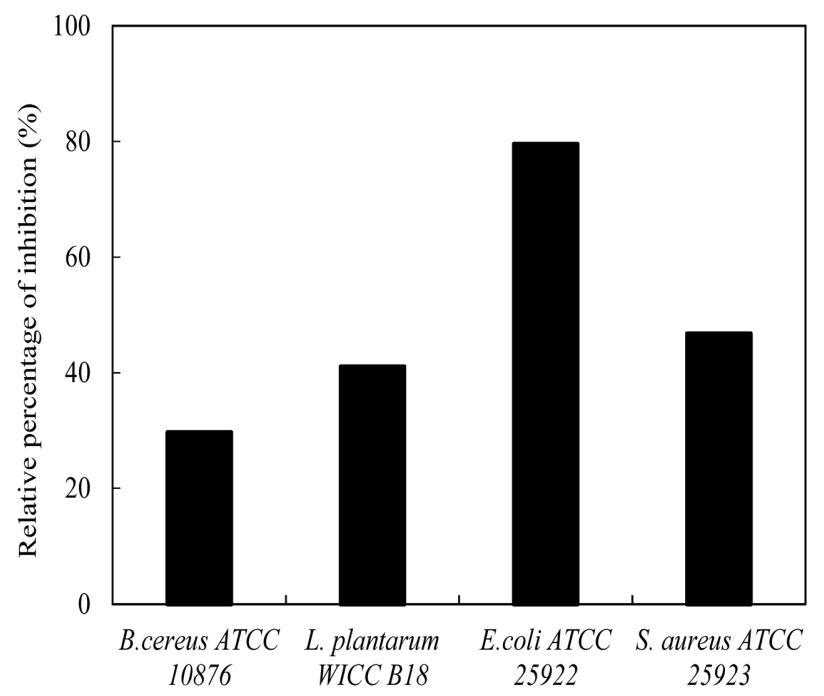

Type of strains

Fig. 3: Relative percentage inhibition of CPAEA MWPA towards all bacteria strains.

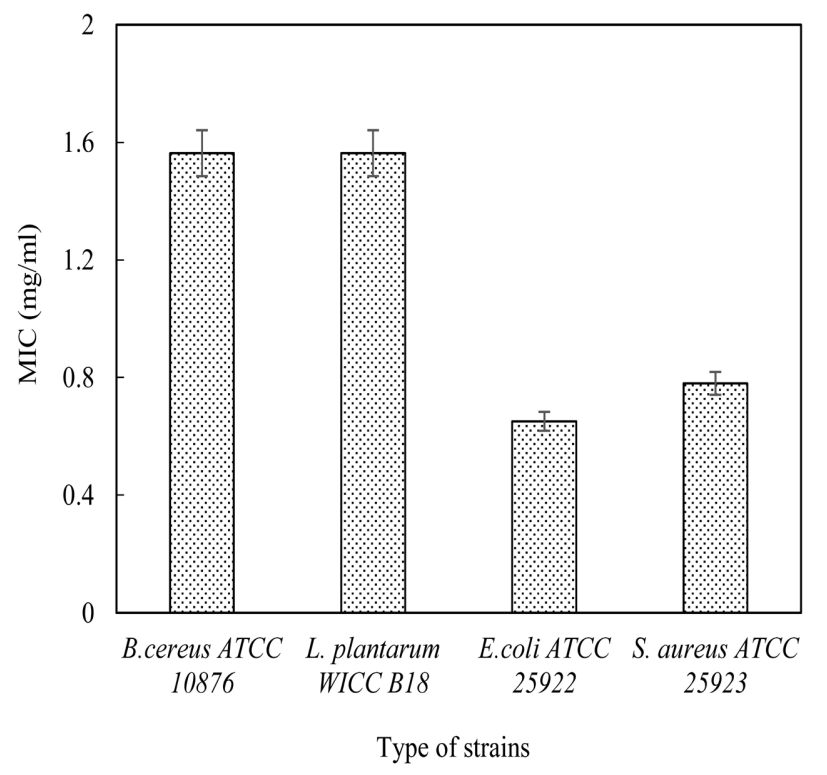

Fig. 4: The MIC value of CPAEA MWPA toward all strains analyzed after $24 \mathrm{hr}$.

\section{Minimum biocidal concentration analysis}

The lowest concentration of antimicrobial agent needed to kill $99.9 \%$ of the particular bacterium normally could be determined using the Minimum Biocidal Concentration (MBC) assay. Results for the determination of MBC for CPAEA against each bacterial strains were as tabulated in Table 3. It was noticed that the MBC values obtained was higher than MIC values in the range of 1.563 to $6.25 \mathrm{mg} / \mathrm{ml}$. The present finding was comparable with previous studies by Elsheikh et al. (2016) and Kang et al. (2011) that reported the MBC values obtained were higher than MIC values against all strains tested. From the table, the value of $\mathrm{MBC}$ against $B$. cereus was determined at $3.125 \mathrm{mg} / \mathrm{ml}\left(6^{\text {th }}\right.$ well) and $1.563 \mathrm{mg} / \mathrm{ml}$ ( $7^{\text {th }}$ well) towards both $S$. aureus and $E$. coli. However, the MBC value for $L$. plantarum was determined at the $5^{\text {th }}$ well which corresponds to the $6.25 \mathrm{mg} / \mathrm{ml}$ of CPAEA. Low MBC values indicate that the plant extract of CPAEA has a strong antimicrobial activity. Kang et al. (2011) suggested that the accumulation of bioactive compounds present in plant extract, such as that in CPAEA, in the bacterial cell membrane fractions resulted in energy depletion and membrane disruption leading to cell damage and lysis. Therefore, findings from MIC and MBC assays help to suggest that the CPAEA has a good potential to be applied as bacteriostatic and bactericidal agents.

Table 3: The biocidal activity and the MBC of CPAEA MWPA against all strains tested after $24 \mathrm{hr}$ incubation at $37^{\circ} \mathrm{C}$.

\begin{tabular}{cc}
\hline Types of bacteria strains & MBC $(\mathbf{m g} / \mathbf{m l})$ \\
\hline B. cereus ATCC 10876 & $3.125 \pm 0.00$ \\
S. aureus ATCC 25923 & $1.563 \pm 0.00$ \\
L. plantarum WICC B18 & $6.25 \pm 0.00$ \\
E. coli ATCC 25922 & $1.563 \pm 0.00$ \\
\hline
\end{tabular}

\section{CONCLUSION}

The ethyl acetate extract of concentrated pyroligneous acid (CPAEA) produced from oil palm fiber (OPF) in optimized condition, showed strong antimicrobial activity when evaluated against both Gram Positive and Gram Negative bacteria. The relative growth inhibition zone was varied between 29 to $79 \%$ with low MIC values of less than $1.6 \mathrm{mg} / \mathrm{ml}$. This further underlines the characteristic of CPAEA as a highly potential natural source for antimicrobial agent.

\section{ACKNOWLEDGMENT}

The authors would like to thank Ministry of Higher Education, Malaysia for the MyBrain Ph.D. scholarship to Fatimatul Zaharah Abas and HiCOE research grant (4J259) as well as Universiti Teknologi Malaysia for the Research University Grant (12H81).

\section{REFERENCES}

Achmadi SS, Mubarik NR, Nursyamsi R, Septiaji P. Characterization of redistilled liquid smoke of oil-palm shells and its application as fish preservatives. Journal of Applied Sciences. 2013; 13(3):401-408.

Araújo E, Pimenta AS, Feijó FM, Castro RV, Fasciotti M, Monteiro TV, Lima KM. Antibacterial and antifungal activities of pyroligneous acid from wood of eucalyptus urograndis and mimosa tenuiflora. Journal of Applied Microbiology. 2018; 124(1):85-96.

Balouiri M, Sadiki M, Ibnsouda SK. Methods for in vitro evaluating antimicrobial activity: A review. Journal of Pharmaceutical Analysis. 2016; 6(2):71-79.

Bandet T, Whitehead S, Blondel-Hill E, Wagner K, Cheeptham N. Susceptibility of clinical Moraxella catarrhalis isolates in British Columbia to six empirically prescribed antibiotic agents. Canadian Journal of Infectious Diseases and Medical Microbiology. 2014; 25(3):155-15. 
Cowan MM. Plant products as antimicrobial agents. Clinical Microbiology Reviews. 1999; 12(4):564-582.

Cunha LC, de Morais SA, de Aquino FJ, Chang R, de Oliveira A, Martins MM, Martins CH, Sousa LC, Barros TT, da Silva CV, do Nascimento EA. Bioassay-guided fractionation and antimicrobial and cytotoxic activities of Cassia bakeriana extracts. Revista Brasileira de Farmacognosia. 2017; 27(1):91-98.

Elshikh M, Ahmed S, Funston S, Dunlop P, McGaw M, Marchant R, Banat IM. Resazurin-based 96-well plate microdilution method for the determination of minimum inhibitory concentration of biosurfactants. Biotechnology letters. 2016; 38(6):1015-1019.

Fullerton M, Khatiwada J, Johnson JU, Davis S, Williams LL. Determination of antimicrobial activity of sorrel (Hibiscus sabdariffa) on Esherichia coli O157: $\mathrm{H} 7$ isolated from food, veterinary, and clinical samples. Journal of medicinal food. 2011; 14(9):950-956.

Huang YF, Chiueh PT, Kuan WH, Lo SL. Microwave pyrolysis of rice straw: Products, mechanism, and kinetics. Bioresource technology. $2013 ; 142: 620-624$

Hyldgaard M, Mygind T, Meyer RL. Essential oils in food preservation: mode of action, synergies, and interactions with food matrix components. Frontiers in microbiology. 2012; 3(12):1-24.

Ibrahim D, Kassim J, Sheh-Hong L, Rusli W. Efficacy of pyroligneous acid from Rhizophora apiculata on pathogenic Candida albicans. Journal of Applied Pharmaceutical Science. 2013; 3(7):7-13.

Ibrahim D, Hong LS, Kuppan N. Antimicrobial activity of crude methanolic extract from Phyllanthus niruri. Natural product communications. 2013b; 8(4):493-496.

Ibrahim D, Kassim J, Lim S, Rusli W. Evaluation of antibacterial effects of Rhizophora apiculata pyroligneous acid on pathogenic bacteria. Malays J Microbiol. 2014; 10:197-204.

Ibrahim D, Lim SH. In vitro antimicrobial activities of methanolic extract from marine alga Enteromorpha intestinalis. Asian Pacific Journal of Tropical Biomedicine. 2015; 5(9):785-788.

Kang CG, Hah DS, Kim CH, Kim YH, Kim E, Kim JS Evaluation of antimicrobial activity of the methanol extracts from 8 traditional medicinal plants. Toxicological research. 2011; 27(1):31-36.

Karou D, Dicko MH, Simpore J, Traore AS. Antioxidant and antibacterial activities of polyphenols from ethnomedicinal plants of Burkina Faso. African Journal of Biotechnology. 2005; 4(8):823-828.

Kumar G, Karthik L, Rao KB. Antibacterial activity of aqueous extract of Calotropis gigantea leaves-an in vitro study. International journal of pharmaceutical Sciences Review and Research. 2010; 4(2):141-144.

Mathew S, Zakaria ZA, Musa NF. Antioxidant property and chemical profile of pyroligneous acid from pineapple plant waste biomass. Process Biochemistry. 2015; 50(11):1985-1992.

Mehmood N, Zubair M, Rizwan K, Rasool N, Shahid M, Ahmad VU. Antioxidant, antimicrobial and phytochemical analysis of cichoriumintybus seeds extract and various organic fractions. Iranian Journal of Pharmaceutical Research: IJPR. 2012; 11(4):1145-1151.

Mirkarimi M, Amin-Marashi SM, Bargrizan M, Abtahi A, Fooladi I, Ali A. The antimicrobial activity of grape seed extract against two important oral pathogens. Zahedan Journal of Research in Medical Sciences. 2013; 15(1):43-46.

Mohapatra DP, Thakur V, Brar SK. Antibacterial efficacy of raw and processed honey. Biotechnology Research International. 2011; 2011:116.

Montazeri N, Oliveira A, Himelbloom BH, Leigh MB, Crapo CA. Chemical characterization of commercial liquid smoke products. Food Science \& Nutrition. 2013; 1(1):102-115.

Nasir B, Fatima H, Ahmed M, Haq IU. Recent trends and methods in antimicrobial drug discovery from plant sources. Austin J Microbiol. 2015; 1(1):1-12.

Naz R, Bano A. Antimicrobial potential of Ricinus communis leaf extracts in different solvents against pathogenic bacterial and fungal strains. Asian Pacific Journal of Tropical Biomedicine. 2012; 2(12):944947.

Rungruang P, Junyapoon S. Antioxidative activity of phenolic compounds in pyroligneous acid produced from Eucalyptus wood. In The 8th International Symposium on Biocontrol and Biotechnology 2010:102106.

Wanderley CD, Faria RT, Ventura MU. Chemical fertilization, organic fertilization and pyroligneous extract in the development of seedlings of areca bamboo palm (Dypsis lutescens). Acta Scientiarum. Agronomy. 2012; 34(2):163-167.

Wiegand I, Hilpert K, Hancock RE. Agar and broth dilution methods to determine the minimal inhibitory concentration (MIC) of antimicrobial substances. Nature Protocols. 2008; 3(2):163-175.

Wei Q, Ma X, Zhao Z, Zhang S, Liu S. Antioxidant activities and chemical profiles of pyroligneous acids from walnut shell. Journal of Analytical and Applied Pyrolysis. 2010; 88(2):149-154.

Yang JF, Yang CH, Liang MT, Gao ZJ, Wu YW, Chuang LY Chemical composition, antioxidant, and antibacterial activity of wood vinegar from litchi chinensis. Molecules. 2016; 21(9):1150:1-10.

Zhai M, Shi G, Wang Y, Mao G, Wang D, Wang Z. Chemical compositions and biological activities of pyroligneous acids from walnut shell. BioResources, 2015; 10(1):1715-1729.

How to cite this article:

Abas FZ, Zakaria ZA, Ani FN. Antimicrobial Properties of Optimized Microwave-assisted Pyroligneous Acid from Oil Palm Fiber. J App Pharm Sci, 2018; 8(07): 065-071. 